
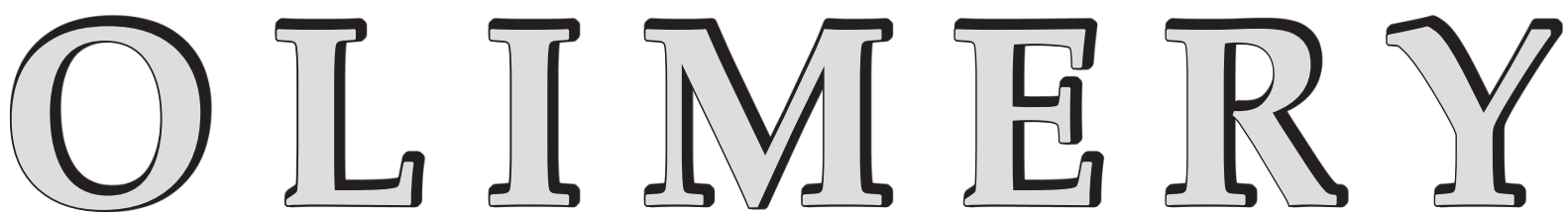

\title{
All-polymer composites - a new approach with the use of disentangled semi-crystalline polymers Part I. Disentangling and properties of disentangled polylactide*)
}

\author{
Justyna Krajenta1), Marta Safandowska ${ }^{1)}$, Andrzej Pawlak ${ }^{1) * *)}$, Andrzej Galeski ${ }^{1)}$ \\ DOI: dx.doi.org/10.14314/polimery.2020.3.1
}

\begin{abstract}
This contribution discusses the preparation of partially disentangled polylactide from solution. The rheological method determined how the density of macromolecular entanglement depends on the concentration of the prepared solution. From a $0.1 \mathrm{wt} \%$ solution, the polymer having $20 \%$ of the original entanglements was obtained. The crystallization studies in isothermal conditions showed that the growth of crystals can be $10 \%$ faster if the polylactide is partially disentangled. For the first time, it was shown that in the partially disentangled polylactide there are shifts in temperatures of crystallization regimes.
\end{abstract}

Keywords: polylactide, macromolecular entanglements, polymer rheology, reptation, isothermal crystallization.

Kompozyty w pełni polimerowe - nowe podejście z użyciem rozplątanych częściowo krystalicznych polimerów

\section{Cz. I. Rozplątywanie i właściwości rozplątanego polilaktydu}

Streszczenie: $\mathrm{W}$ artykule omówiono otrzymywanie z roztworu częściowo rozplątanego polilaktydu. Metodą reologiczną określono gęstość splątań makrocząsteczek w funkcji stężenia sporządzonego roztworu. $Z$ roztworu o stężeniu 0,1\% mas. otrzymano polimer zawierający ok. 20\% wyjściowych splątań. Na podstawie wyników badań procesu krystalizacji w warunkach izotermicznych stwierdzono, że wzrost kryształów może być o $10 \%$ szybszy w przypadku tylko częściowego splątania polilaktydu. Po raz pierwszy wykazano, że w częściowo rozplątanym polilaktydzie występuje przesunięcie wartości temperatury, w których następuje zmiana reżimu krystalizacji.

Słowa kluczowe: polilaktyd, splątania makrocząsteczek, reologia polimerów, reptacja, krystalizacja izotermiczna.

\footnotetext{
1) Polish Academy of Sciences, Centre of Molecular and Macromolecular Studies, Sienkiewicza 112, 90-363 Lodz, Poland.

*) The part of article was presented at the Pomerania-Plast 2019 Conference, June 5-7, 2019, Międzyzdroje, Poland.

**) Author for correspondence: apawlak@cbmm.lodz.pl
} 
Entanglements of macromolecules affect a number of polymer behaviors, among others rheological, mechanical and crystallization from the melt. It is assumed that in typically processed polymer there is an equilibrium density of entanglements, characterized by the average molecular mass between entanglements, $M_{e}$. This mass is equal $1200-1300 \mathrm{~g} / \mathrm{mol}$ for polyethylene, but up to $20000 \mathrm{~g} / \mathrm{mol}$ for polystyrene [1, 2].

At present there are two groups of methods available for limiting the density of entanglements of macromolecules and thus influencing the properties of the polymer [2]. The first group of methods is based on polymerization at low temperatures with the simultaneous crystallization of the resulting polymer. The second group of methods applies to the initially equilibrium entangled polymers. It is known that in a dilute solution the macromolecular chains form coils with a limited number of contacts and entanglements. It is crucial to convert the disentangled polymer from the solution to a solid state, while avoiding the re-entangling of the chains. This can be achieved by the controlled cooling of the hot solution with the passage through the gelation phase, in which the crystals that stabilize the disentangled structure are formed. This approach is used for polypropylene [3]. Alternatively, the dilute solution can be rapidly frozen in liquid nitrogen and then the solvent will be sublimed at low temperatures, or the non-solvent can be added to the frozen solution and the polymer precipitated. This method can be used, for example, in the disentangling of polylactide [4].

There are two main models describing the dynamics of the polymer chain in polymers: Rouse model and tube model. The tube model, with many modifications, better describes the motion of high molecular mass entangled polymer in melt or in concentrated solution $[5,6]$. In this model a polymer chain moves inside a virtual tube, with a diameter depending on the restrictions made by other macromolecules. The snake-like movements of the macromolecule are referred to as reptation [7]. In the simplest version of this model, the motion of a macromolecule along the tube is free, but its motion perpendicular to the tube is restricted by the tube wall. The time of diffusion normalized to the length of tube is an important parameter describing the dynamics of a polymer chain. The relaxation time of the motion of chain $\tau_{d^{\prime}}$ corresponding to the chain exit from the tube, i.e. disentangling, is described by the equation:

$$
\tau_{d} \sim \tau_{s} M^{3} / M_{e}
$$

where: $\tau_{s}$ - the relaxation time in monomeric scale $\left(\sim 10^{-11} \mathrm{~s}\right)$ dependent on the reciprocal of temperature, $M-$ the molecular mass, $M_{e}$ - the average molecular mass between entanglements [6].

Many experimental results can be satisfactorily described by the tube model.

Relaxation of the shear modulus $G_{s}$ has the form within the tube model [6]:

$$
G_{s}(t)=\frac{g \varrho R T}{M_{e}}(t)=G_{N}^{0} m(t)
$$

where: $g$ - the numerical factor (equal to 1 or equal to $4 / 5$ when the effects of chain slippage through the links are taken into account), $\mathrm{Q}-$ density, $R$ - the gas constant, $T$-absolute temperature, $m(t)$ - the relaxation function, $t-$ time, $G_{N}^{0}$ - the modulus in the rubbery plateau region [8].

In the simplest version of the model, the relaxation function $m(t)$ is described by equation:

$$
m(t)=\frac{8}{\pi^{2}} \sum_{p: o d d} \exp \left(\frac{-p^{2} t}{\tau_{d}}\right)
$$

Usually the $G_{s}(t)$ function is not determined experimentally, but calculated from the dependence:

$$
G^{\prime}(\omega)=\omega \int_{0}^{\infty} G_{s}(t) \sin (\omega t) d t
$$

where: $\omega$ - frequency, $G^{\prime}$ - storage modulus.

More advanced models of the relaxation function $m(t)$ are available as well. The example is a polydisperse double reptation model, developed by Likhtman and McLeish $[9,10]$. It is based on the tube model and incorporates contour length fluctuations, constraint release (assuming double reptation) and longitudinal stress relaxation along the tube. Likhtman and McLeish proposed the following form of $m(t)$ :

$$
\begin{gathered}
m(t)=\frac{4}{5} \mu(t) R(t)+\frac{1}{5 Z} \sum_{p=1}^{Z-1} \exp \left(\frac{-p^{2} t}{\tau_{R}}\right)+ \\
+\frac{1}{Z} \sum_{p=Z}^{N} \exp \left(\frac{-2 p^{2} t}{\tau_{R}}\right)
\end{gathered}
$$

where: $\mu(t)$ - the remaining fraction of the initial tube, $R(t)$ - the relaxation function due to constraint release, $Z=M / M_{e^{\prime}} \tau_{R}-$ the Rouse time of the chain in its tube.

The majority of research on the relationship between the density of entanglements and properties was carried out for polyethylene [2]. It can be concluded that the reduction of the entanglements results in the decrease in the values of rheological modules. The disentangled polymer is also easier to deform, with a slower build-up of forces in the self-reinforcement phase of deformation. It was also observed that crystallization is faster for a partially entangled polymer.

Little attention has been paid to the properties of disentangled polylactide. Poly(L-lactide) (PLA) is a biopolymer, exhibiting a good mechanical performance, biodegradability, and biocompatibility [11]. The polymer can crystallize in isothermal conditions, forming spherulites. PLA with a limited density of entanglements was obtained by the freeze-drying of its dilute solutions: in xylene (0.05-10 wt \%) [12], 1,4 dioxane $(0.07-5$ wt \%) [13, 14] or 
methylene chloride $\left(0.0005-0.5 \mathrm{~g} / \mathrm{cm}^{3}\right)$ [4]. Unfortunately, the rheology of disentangled PLA has not been studied so far. The only exception is Liu's paper [4] where it was shown that the storage modulus of PLA obtained from $0.005 \mathrm{~g} / \mathrm{mol}$ solution has a plateau value of $118 \mathrm{kPa}$, which corresponds to $M_{e}=39000 \mathrm{~g} / \mathrm{mol}$.

A little bit more is known about the crystallization of partially disentangled polylactide. The isothermal crystallization of partially disentangled PLA was studied by Liu et al. [4]. Their observations were limited only to the temperature range when the measured growth rate of spherulites decreases with the increasing of temperature. It was showed that spherulites grew faster with a decreased concentration of precursor solution. The authors also observed a reduction in the rate of growth if the disentangled polymer was annealed at high temperature in the melt.

The partially disentangled PLA, heated inside the DSC cell, exhibited cold crystallization (or reorganization), with a lower exotherm at $78{ }^{\circ} \mathrm{C}$ and with broad exotherm between $110-155{ }^{\circ} \mathrm{C}$. Only the second range was observed for a reference bulk sample [13]. The depression of cold-crystallization temperature (when compared to the bulk material) has been observed even for the samples obtained from highly concentrated solutions (i.e. $7 \mathrm{wt} \%$ ) [14].

Many years ago, Lemstra and co-workers [15] showed that it is possible to obtain fibers with very good mechanical properties from a dilute solution of polymer. This is due to the fact that large deformations can be achieved in a polymer with a limited density of entanglements. Galeski et al. [16, 17] proposed using such a polymer in the preparation of a nanocomposite by blending it with a second, molten polymer. In the mixing process carried out at high temperature, but below the melting temperature of the partially disentangled polymer, the forces are transmitted to it, resulting in the grain refinement and causing the plastic deformation, leading to the transformation of the lamellar structure into micro and nano-size fibers. In this way, during the mixing in standard processing devices, fibrous fillers are formed, dispersed in the melt of the second polymer. After lowering the temperature at the end of the mixing, an all-polymer composite is formed.

The polylactide is an attractive material because it is obtained from natural resources and can be recycled by composting after use. PLA is also relatively easy to disentangle. Therefore, when continuing the work on the disentangled polymers, we chose it for disentangling, for the studies of the influence of entanglements on polymer properties and finally to explore the possibility of using this polymer to produce a nanocomposite, by the method of mixing it with a second biodegradable polymer. The studies of disentangled polylactide are described in two articles. The first one is devoted to the preparation and characterization of partially disentangled polylactide, the following contribution describes the mechanical properties of it and use of disentangled PLA for preparation of polymer composites.

\section{EXPERIMENTAL PART}

\section{Materials}

Poly (L-lactide) NW 4032D, produced by Nature Works, was used in these researches. It contained 1.15\% of D-lactide. Molecular mass measurements using GPC-MALLS gave the following values: $M_{n}=72000 \mathrm{~g} / \mathrm{mol}$, $M_{w}=88000 \mathrm{~g} / \mathrm{mol}$.

\section{Disentangling of PLA}

A procedure similar to that described by Liu et al. [4] was used to disentangle the polylactide. PLA solutions in methylene chloride were prepared at concentrations of $10,0.5$ and $0.1 \mathrm{wt} \%$. Mixing was carried out in a flask with a mechanical stirrer, for $40 \mathrm{~min}$ at $25{ }^{\circ} \mathrm{C}$. The homogeneous solution was poured into a large volume of liquid nitrogen. Then, ethanol was added to the frozen solution in a volume five times higher than the volume of the solution, causing the precipitation of polylactide in the form of a white powder. The final step was to remove the residue of methylene chloride and ethanol during drying for about 8 hours under vacuum at room temperature.

According to theoretical considerations, a polylactide from a $10 \mathrm{wt} \%$ solution should maintain the equilibrium density of entanglements, while a polymer from the lower concentrations, i.e. 0.5 and $0.1 \mathrm{wt} \%$, should be partially disentangled. The polylactides that we tested were designated PLA10, PLA0.5 and PLA0.1, where the number indicated the concentration of the solution from which the solid PLA was obtained. The PLAi designation refers to the initial polylactide in the form of pellets.

\section{Methods of testing}

- The characterization of partially disentangled PLA was performed by studying their rheology and crystallization processes. Rheological tests were carried out using the Ares rotational rheometer (TA Instruments), in the plate-plate configuration, changing the frequency in the range $0.1-512 \mathrm{rad} / \mathrm{s}$, at $180{ }^{\circ} \mathrm{C}$, with $1 \%$ strain. The thickness of the samples was $1 \mathrm{~mm}$.

- Using the Linkam TMS 92 heating stage connected to the polarizing microscope and the video recording system, observations of the isothermal crystallization processes were carried out. A small amount of PLA powder was placed between two microscope slides, melted at $180{ }^{\circ} \mathrm{C}$ and slightly compressed. A film with a thickness of $10-15 \mu \mathrm{m}$ was obtained in this way. Then, the temperature was lowered to a selected range of $120-155^{\circ} \mathrm{C}$, and the formation of a spherulitic structure was observed: the spherulite nucleation density, growth rate of spherulites and occurrence of crystallization regimes were determined. 
- According to Hoffman's theory of crystallization [18] the equation describing the growth rate of spherulites $(G)$, may be presented in the logarithmic form:

$$
\log G+\frac{\Delta E}{2.3 \times R\left(T_{c}-T_{\infty}\right)}=f\left(\frac{1}{T_{c} \Delta T}\right)
$$

where: $\Delta E$ - the activation energy for the transportation of the polymer segments to the site of crystallization, $R$ - the gas constant, $T_{c}$ - the crystallization temperature, $T_{\infty}$ - the extrapolated temperature when a free volume is close to zero, somewhat below the glass transition temperature, $\Delta \mathrm{T}=T_{m}{ }^{\mathrm{o}}-T_{c}$ - the undercooling, $T_{m}{ }^{\mathrm{o}}$ - the equilibrium melting point.

This dependence has a linear character, with the slopes of the sectors changing at characteristic temperatures, defining the ranges of crystallization regimes. The following values were taken for the calculations of the transition between the regimes: $\Delta \mathrm{E}=6280 \mathrm{~J} / \mathrm{mol}, T_{m}{ }^{\circ}=485.2 \mathrm{~K}$ [19], $R=8.31 \mathrm{~J} /(\mathrm{mol} \cdot \mathrm{K})$, and $T_{\infty}=303.2 \mathrm{~K}$.

\section{RESULTS AND DISCUSSION}

The polylactides prepared from solutions were the subject of rheological tests. The aim was to confirm the achievement of the decreased density of macromolecular entanglements in the obtained materials. Figure 1 shows the changes of the storage modulus $G^{\prime}$ with the frequency for the partially disentangled PLA samples measured in the rheometer at $T=180^{\circ} \mathrm{C}$. A decrease in the value of the module in high frequencies for polymers prepared from more dilute solutions is visible. This reduction is interpreted as a result of a decrease in the density of macromolecular entanglements.

At high frequencies, the values of the $G^{\prime}$ approach the plateau, described by the $G_{N}^{0}$ modulus. According to Eq. (2), knowing the $G_{N}^{0}$ it is possible to determine the density of entanglements between macromolecules $\left(M_{e}\right)$,

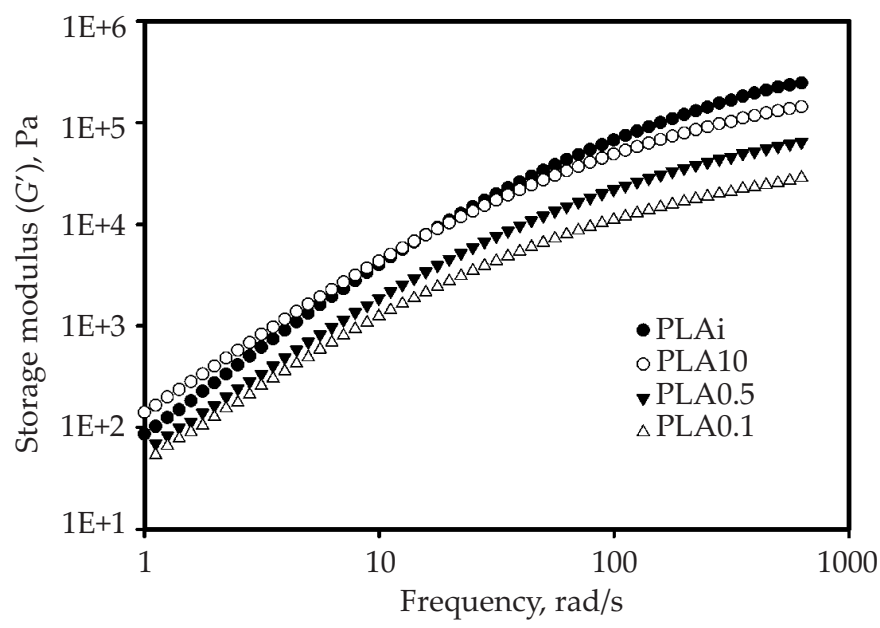

Fig. 1. The storage modulus $G^{\prime}$ as a function of frequency, measured at $180^{\circ} \mathrm{C}$ assuming the density of polymer is equal to $1.21 \mathrm{~g} / \mathrm{cm}^{3}$. Like in many other polymers [20, 21], the plateau for the PLA was not achieved, so the values of $G_{N}^{0}$ modulus were determined by the method proposed for polypropylene by Eckstein et al. [22]. This method uses the results of the measurements of the loss modulus $G^{\prime \prime}$, which is associated with the modulus $G_{N}^{0}$ with the equation:

$$
G_{N}^{0}=\frac{4}{\pi} \times \int_{-\infty}^{\omega_{\max }} G^{\prime \prime}(\omega) \mathrm{d} \ln (\omega)
$$

where: $\omega_{\max }$ - the frequency at which $G^{\prime \prime}$ has a maximum.

Using Eqs (7) and (2), the mean molecular masses between the entanglements of macromolecules were determined. Their values are shown in Table 1, as well as for the fully entangled PLAi.

T a b l e 1. The plateau storage modulus $G_{N^{\prime}}^{0}$ and molecular mass between entanglements $M_{e}$

\begin{tabular}{c|c|c}
\hline Sample & $\begin{array}{c}G_{N}^{0} \\
\text { Pa }\end{array}$ & $\begin{array}{c}M_{e} \\
\mathrm{~g} / \mathrm{mol}\end{array}$ \\
\hline PLAi & 432900 & 10500 \\
PLA10 & 278000 & 16300 \\
PLA0.5 & 138800 & 32800 \\
PLA0.1 & 69700 & 65300 \\
\hline
\end{tabular}

In the literature, $M_{e}$ values in the 4000-10 $500 \mathrm{~g} / \mathrm{mol}$ range can be found for a fully entangled polymer [23-25]. The large dispersion of results is often found when different brands of polymer are measured in different laboratories. The molecular mass $M_{e}=10500 \mathrm{~g} / \mathrm{mol}$ measured for PLAi is at the upper limit of the literature results. Because it was a risk that the PLA samples obtained from solutions may re-entangle during hot pressing of the powder, the discs for rheological studies were made by sintering, i.e. by compressing the PLA powders in a temperature below the melting point. The use of such samples slightly increases the values of $M_{e^{\prime}}$ for example by $5 \%$ for polypropylene [26].

The analysis of the $M_{e}$ masses in Table 1 shows that polymers prepared from more diluted solutions are really less entangled and thus have higher values for these masses. The greatest mass between entanglements, $65300 \mathrm{~g} / \mathrm{mol}$, was measured for PLA0.1 and it is close to the molecular mass of the polymer $(88000 \mathrm{~g} / \mathrm{mol})$. From the comparison of $M_{e}$ and $M_{w}$ it follows that in a fully entangled PLAi there are 8-9 entanglements per macromolecule. In the most disentangled PLA0.1 there are only 1-2 entanglements per macromolecule.

The rheological results can be described using one of the modified tube models, for example by the model described by Eq. (5). Using a free software developed by Likhtman [10], we attempted to fit the experimental data of $G^{\prime}(t)$ and $G^{\prime \prime}(t)$. The results of the calculation for PLAi and PLA0.5 are shown in Fig. 2. 


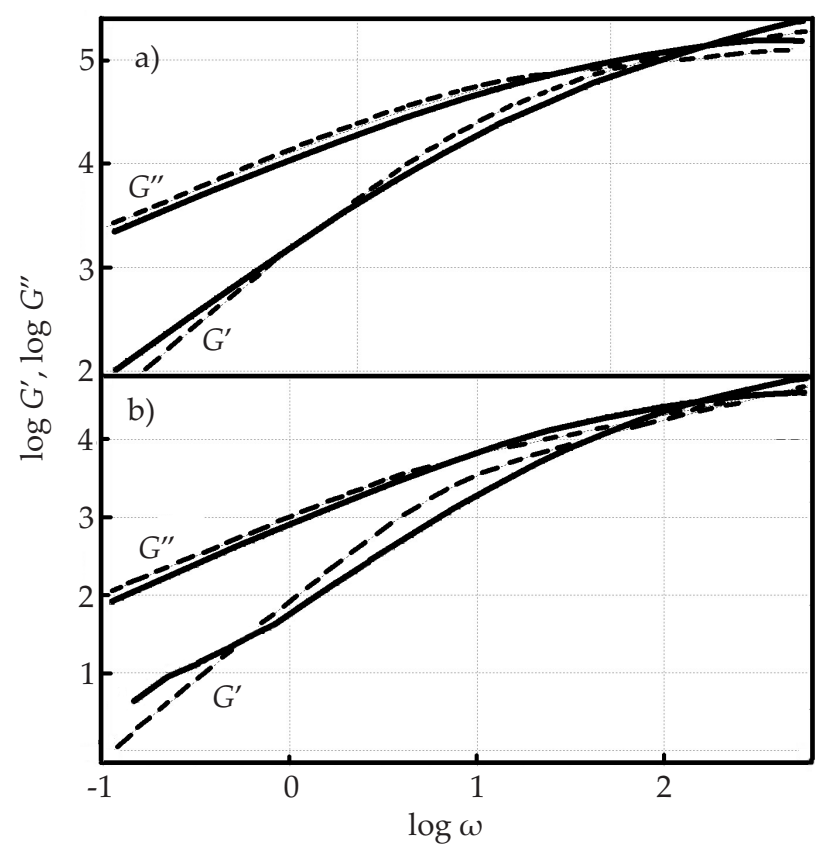

Fig. 2. The rheological properties of: a) PLAi, b) PLA0.5; the solid lines represent the experimental results for the storage modulus $G^{\prime}$ (see Fig. 1) and the loss modulus $G^{\prime \prime}$; the dashed lines were calculated by means of the tube model

Although a relatively good approximation of the experimental data was obtained for the entangled PLAi and PLA10 (data not shown here), in the case of the disentangled polymers it was not possible to get a good description of the experimental results based on Eq. (5). In the case of PLAi, the relaxation time was $2 \cdot 10^{-4} \mathrm{~s}$, but for disentangled polymers the time unexpectedly increased: to $39 \cdot 10^{-4} \mathrm{~s}$ for PLA10, $280 \cdot 10^{-4} \mathrm{~s}$ for PLA0.5 and $697 \cdot 10^{-4} \mathrm{~s}$ in the case of PLA0.1, which does not seem to be appropriate. Attempts to use several other models described in [6] (i.e. DE, DECLF and ER3) also did not give fully satisfactory results. Probably, for the disentangled polymers, more advanced models should be used than those used for fully entangled polymers [6].

The polylactide selected for these studies crystallize relatively easy under the isothermal conditions and form a spherulitic structure. It is expected that the reduction of entanglements density will modify the transport of macromolecules to the crystallization front, and thus the process of crystallization will be faster. The crystallization of partially disentangled PLA was only carried out by Liu et al. [4] in a limited temperature range $\left(130-142{ }^{\circ} \mathrm{C}\right)$ and focused on the spherulite growth. This range has been extended to $120-155^{\circ} \mathrm{C}$ to describe the course of the crystallization process at temperatures where the crystallization regimes change and to be on the both sides of the maximum in the spherulite crystallization rate, measurable for PLA. Figure 3 shows how the spherulites growth rate $G$, as measured from positions of their boundaries with time, depends on the crystallization temperature and degree of disentangling of the macromolecules.

In the entire temperature range, spherulite growth rates were higher in polymers obtained from more dilute

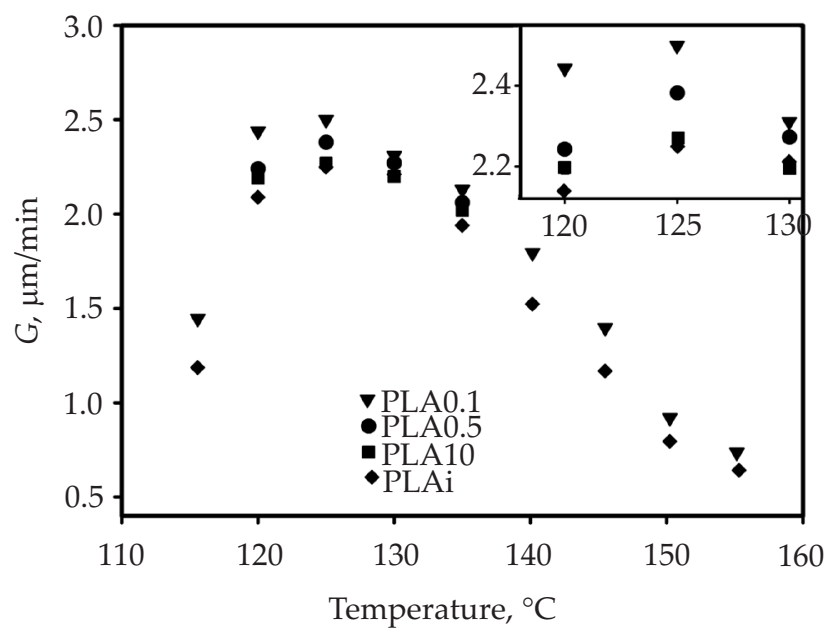

Fig. 3. Growth rate of PLA spherulites $(G)$ as a function of the crystallization temperature; the insert shows the enlarged part of the graph for the range of the highest growth rates

solutions. For example, at the crystallization temperature of $125^{\circ} \mathrm{C}$, this rate was $2.25 \mu \mathrm{m} / \mathrm{min}$ for PLAi and as much as $2.48 \mu \mathrm{m} / \mathrm{min}$ for the disentangled PLA0.1. The maximum spherulite growth rate occurred at a temp. of $125^{\circ} \mathrm{C}$ in all materials tested. The higher growth rates of spherulites in materials obtained from more diluted solutions confirm that in PLA, similarly to PE and PP, the disentangling of macromolecules facilitates the process of crystallization from the melt.

The precise measurements of the spherulite growth rate for PLA0.1 at temp. of 130 and $155^{\circ} \mathrm{C}$ showed that it is maintained for up to 4 hours. This means that in this temperature range no effect of possible degradation of the polymer or re-entangling of macromolecules was observed. However, at higher temperatures, e.g. at $180^{\circ} \mathrm{C}$, the faster motions of macromolecules in the melt should lead to an increase in the density of the entanglements with the time of residence at this temperature. It was measured how the spherulite growth rate changes if the polymer has been preheated for a longer time in the melt prior to crystallization. This is illustrated in Fig. 4, in which the growth rates of spherulites of the partially disentangled PLAs at $135^{\circ} \mathrm{C}$ were related to the spherulite growth rate of PLAi at the same temperature. All materials were annealed in the melt before crystallization. The annealing time at $180^{\circ} \mathrm{C}$ was increased from 1 to $30 \mathrm{~min}$. The growth rate for PLAi remained constant even after 30 minutes of annealing, while in partially disentangled polymers the growth rate gradually decreased with the time of annealing and after about 30 minutes it was similar to that for PLAi. The slightly disentangled PLA10 showed a constant growth rate, but at a slightly elevated level.

We also investigated how the nucleation of spherulites changes depending on the degree of macromolecular entanglement and the time of annealing in the melt. Because PLA nucleation is mainly heterogeneous, PLAi which had a different processing history then the others, was not analyzed. Figure 5 shows that the density of nu- 


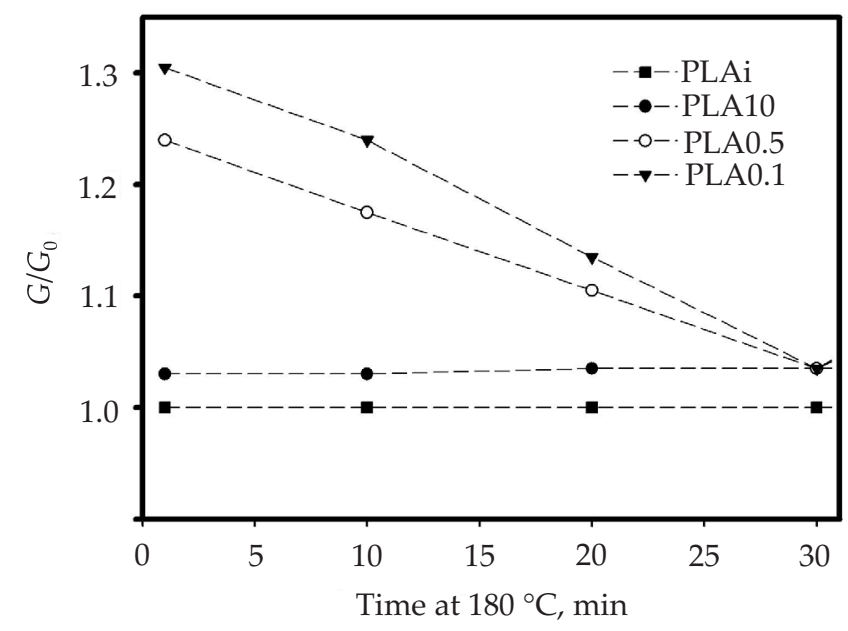

Fig. 4. Growth rate of spherulites of disentangled polymers $(G)$ related to the constant growth rate of PLAi $\left(G_{0}\right)$; measurements were performed at $135^{\circ} \mathrm{C}$ after annealing of samples at $180^{\circ} \mathrm{C}$

clei decreases with the disentangling level and in PLA0.1 it is a half of the nucleation density in PLA10. The nucleation density decreases rapidly with the time of annealing the polymer at $180^{\circ} \mathrm{C}$ before crystallization and also the differences between materials disappears. After 60 minutes the differences between PLA10, PLA0.5 and PLA0.1 are no longer visible. The changes in the spherulite nucleation resemble those previously observed in polypropylene [27]. An additional observation from the research of samples annealed over a longer time is the beginning of the degradation of PLA0.1 after 90-120 min of annealing, as evident in the gradual increase in growth rate, $G$, and density of the nucleation.

Polylactide, like other crystallizing polymers, is characterized by the presence of crystallization regimes, limited

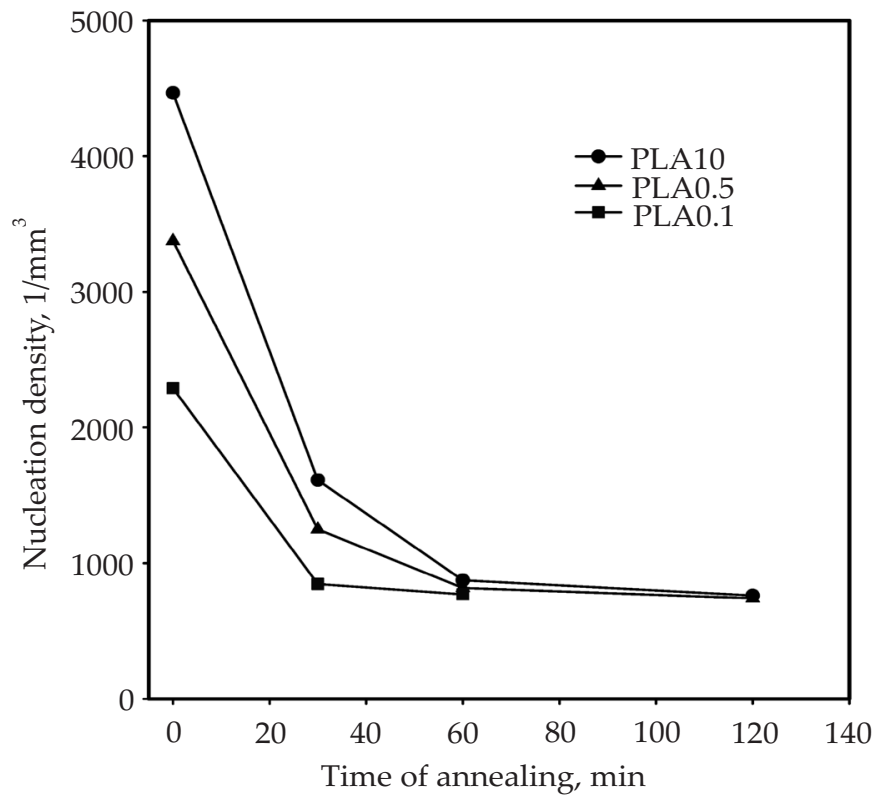

Fig. 5. The density of spherulite nuclei measured during crystallization at $135^{\circ} \mathrm{C}$ after annealing the polymer for various times at the temperature of $180^{\circ} \mathrm{C}$
$\mathrm{T}$ a $\mathrm{b} 1 \mathrm{e} 2$. Temperatures of transitions between regimes of crystallization

\begin{tabular}{c|c|c}
\hline \multirow{2}{*}{ Polymer } & \multicolumn{2}{|c}{ Temperature of transition, ${ }^{\circ} \mathrm{C}$} \\
\cline { 2 - 3 } & Regime I-II & Regime II-III \\
\hline PLAi & 153.0 & 119.3 \\
PLA0.1 & 151.0 & 118.3 \\
PLA0.1, annealed & 153.0 & 119.3 \\
20 min at $180^{\circ} \mathrm{C}$ & & \\
\hline
\end{tabular}

by the characteristic transition temperatures. The exact course of crystallization at the lamellar level depends on the temperature regime in which it takes place. The measured spherulite growth rates were used to determine the transition temperatures between the crystallization regimes, according to Eq. (6). Usually, three regimes are distinguished in a polylactide, with 120 and $147-163{ }^{\circ} \mathrm{C}$ transition temperatures, depending on the specific type of PLA [28]. For the first time, the transitions temperatures for partially disentangled polylactides were determined and the results are presented in Table 2 .

The error for the temperature calculation is estimated at $\pm 0.1{ }^{\circ} \mathrm{C}$. As it can be seen from Table 2, for the disentangled PLA0.1 the transition temperature from Regime II to III is $1^{\circ} \mathrm{C}$ lower, and from Regime I to II is $2^{\circ} \mathrm{C}$ lower than for fully entangled PLAi. This means that in a wider range of temperatures the growth of crystal is possible in accordance with a mechanism leading to a more regular building of lamella. For example, in a disentangled polymer at $T=152{ }^{\circ} \mathrm{C}$ we have a crystallization according to the Regime I scheme, but in the entangled PLAi the transport of macromolecules is limited by more entanglements and this leads to the crystallization in Regime II.

If PLA0.1 was subjected to annealing in the melt at $180{ }^{\circ} \mathrm{C}$, after 20 minutes the material exhibited transition temperatures characteristic of fully entangled polylactide.

\section{CONCLUSIONS}

Polylactide can easily be disentangled at room temperature using methylene chloride as a solvent. Rheological research has shown that even at concentration of $10 \mathrm{wt} \%$ of polymer in the solution, a material with a limited (in comparison to the fully entangled) density of entanglements of macromolecules is obtained after solidification. If the concentration in the solution was $0.1 \mathrm{wt} \%$, the average number of entanglements of the macromolecule has been reduced to $1-2$, i.e. about 5-6 times less than in the entangled polymer. The reduced density of entanglements caused a decrease in the value of rheological modules: loss and storage.

As with the previously examined polypropylene, the reduction in the density of entanglements affects the crystallization process. Under isothermal conditions, easier transport of macromolecules to the crystallization front is observed and, as a result, a faster growth of the lamellae occurs, which is measurable by the growth rate 
of spherulites. In a wide temperature range of $115-150{ }^{\circ} \mathrm{C}$, a $10-15 \%$ increase in the spherulite growth rate was observed if the polymer was significantly disentangled. It has also been noticed that due to the easier movement of macromolecules in the melt, the temperatures of the crystallization regimes are shifting and as a result, crystals with more regular architecture can be formed at temperatures of $1-2{ }^{\circ} \mathrm{C}$ lower.

If the polymer is kept at a high temperature for a long time, it gradually re-entangles. This phenomenon was visible in PLA after about 20-30 min as a decrease in the spherulite growth rate and a shift of the transition temperatures between regimes to the values typical for fully entangled polylactide.

The project was financed from the funds of the National Science Centre, Poland on the basis of the decision number UMO-2015/19/B/ST8/03870.

\section{REFERENCES}

[1] Fetters L.J., Lohse D.J., Richter D. et al.: Macromolecules 1994, 27, 4639. http://dx.doi.org/10.1021/ma00095a001

[2] Pawlak A.: Macromolecular Chemistry and Physics 2019, 1900043.

http://dx.doi.org/10.1002/macp.201900043

[3] Pawlak A., Krajenta J., Galeski A.: Journal of Polymer Science. Part B. Polymer Physics 2017, 55, 748. http://dx.doi.org/10.1002/polb.24328

[4] Liu X.-T., Bao R., Li Y. et al.: Journal of Polymer Research 2016, 23, 164. http://dx.doi.org/10.1007/s10965-016-1060-z

[5] Doi M.: "Materials Science and Technology. A Comprehensive Treatment" (Eds. Cahn R.W., Haasen P., Kramer E.J.), Volume 12. "Structure and Properties of Polymers" (Ed. Thomas E.L.), VCH Verlag, Weinheim 1993, pp. 389-425.

[6] Zulli F., Giordano M., Andreozzi L.: Rheologica Acta 2015, 54, 185. http://dx.doi.org/10.1007/s00397-014-0827-6

[7] DeGennes P.G.: Journal of Chemical Physics 1971, 55, 572. http://dx.doi.org/10.1063/1.1675789

[8] Ferry J.D.: "Viscoelastic properties of polymers", John Wiley \& Sons, New York 1981, p. 552.

[9] Likhtman A.E., McLeish T.C.B.: Macromolecules 2002, 35, 6332 . https://doi.org/10.1021/ma0200219

[10] RepTate software. Developed by Likhtaman A. Version 2009.

https://blogs.upm.es/compsoftmatter/software/reptate-old/

[11] Duda A., Penczek S.: Polimery 2003, 48, 16. http://dx.doi.org/10.14314/polimery.2003.016

[12] Hao H., Liu R., Zhao Y.: Polymers \& Polymer Composites 2009, 17, 31. https://doi.org/10.1177/096739110901700104

[13] Sasaki T., Yamauchi N., Irie S. et al.: Journal of Polymer Science. Part B. Polymer Physics 2005, 43, 115. http://dx.doi.org/10.1002/polb.20314

[14] Sasaki T., Morino D., Tabata N.: Polymer Engineering and Science 2011, 51, 1858.

http://dx.doi.org/10.1002/pen.21977

[15] Smith P., Lemstra P.J.: Macromolecular Chemistry and Physics 1979, 180, 2983. https://doi.org/10.1002/macp.1979.021801220

[16] Krajenta J., Pawlak A., Galeski A.: Polimery 2015, 60, 10. http//dx.doi.org/10.14314/polimery.2015.664

[17] Krajenta J., Pawlak A., Galeski A.: Journal of Polymer Science. Part B. Polymer Physics 2016, 54, 1983. http://dx.doi.org/10.1002/polb.24105

[18] Hoffman J.D.: Polymer 1983, 24, 3. http://dx.doi.org/10.1016/0032-3861(83)90074-5

[19] Bojda J., Piorkowska E., Lapienis G. et al.: European Polymer Journal 2018, 105, 126. http://dx.doi.org/10.101/j.eurpolymj.2018.05.017

[20] Wu S.: Journal of Polymer Science. Part B. Polymer Physics 1989, 27, 723. http://dx.doi.org/10.1002/polb.1989.090270401

[21] Liu C.Y., He J., van Ruymbeke E. et al.: Polymer 2006, $47,4461$. http://dx.doi.org/10.1016/j.polymer.2006.04.054

[22] Eckstein A., Suhm J., Friedrich C. et al:: Macromolecules 1998, 31, 1335. http://dx.doi.org/10.1021/ma971270d

[23] Dorgan J.R., Janzen J., Clayton M.P.: Journal of Rheology 2005, 49, 607 . http://dx.doi.org/10.1122/1.1896957

[24] Cooper-White J.J., MacKay M.E.: Journal of Polymer Science. Part B. Polymer Physics 1999, 37, 1803. h t t p://dx.doi.org / 10.1002 / ( S I C I ) 1099 0488(19990801)37:15<1803::AID-POLB5>3.0.CO;2-M

[25] Grijpma D.W., Penning J.P., Pennings A.J.: Colloid \& Polymer Science 1994, 272, 1068. http://dx.doi.org/10.1007/BF00652375

[26] Pawlak A., Krajenta J., Galeski A.: Polymer 2018, 151, 15. https://doi.org/10.1016/j.polymer.2018.07.033

[27] Krajenta J., Safandowska M., Pawlak A.: Polymer 2019, 175, 215. https://doi.org/10.1016/j.polymer.2019.05.015

[28] Saeidlou S., Huneault M.A., Li H. et al.: Progress in Polymer Science 2012, 37, 1657. http://dx.doi.org/10.1016/j.progpolymsci.2012.07.005 Received 3 IX 2019. 